\title{
Induction of fibrogenesis by lung antibody-treated macrophages
}

\author{
DANIEL M. LEWIS and ROBERT BURRELL \\ Department of Microbiology, West Virginia University Medical Center, Morgantown, \\ West Virginia, USA
}

\begin{abstract}
Lewis, D. M. and Burrell, R. (1976). British Journal of Industrial Medicine, 33, 25-28. Induction of fibrogenesis by lung antibody-treated macrophages. Using a modification of an in vitro model of fibrogenesis, lung connective tissue antibodies have been shown to stimulate macrophages to release a collagen stimulating factor acting on fibroblast target cells. This stimulation was measured by increased hydroxyproline production from fibroblasts that had reached stationary growth phase. In subcytotoxic amounts, this antibody had no such effect directly on fibroblasts. These findings further illustrate the value of studying fibrogenesis by the in vitro method.
\end{abstract}

Circulating antibodies to lung connective tissue have been shown to occur spontaneously in a number of chronic lung diseases (Burrell, Wallace, and Andrews, 1964). By passively administering homologously-derived lung antibodies in experimental animals, several effects on normal lung structure and function have been described (Burrell et al., 1974). Since it is known that these antibodies are capable of reacting with fibroblasts and other connective tissue elements (Burrell et al., 1966; Esber and Burrell, 1970), it remained to be determined if there was any relationship between the presence of these antibodies and fibrogenicity in diseases such as coalworkers' pneumoconiosis.

An excellent in vitro model exists for the study of fibrogenesis in fibroblast cell cultures (Heppleston and Styles, 1967). In this model, silica dust treated macrophage supernates were shown to stimulate collagen production in fibroblast target cells as evidenced by increased hydroxyproline production. This report gives results of the examination of the effect of lung antibodies on fibroblasts, using this model.

\footnotetext{
*Supported in part by the Charles McCamic Foundation of Wheeling, West Virginia, and by National Occupational Safety and Health Grant $\mathrm{OH} 00360$.
}

\section{Materials and methods}

\section{Lung antibodies}

Homologously-derived lung connective tissue antibodies were produced by stimulating the production of ascitic fluid in appropriately immunized mice according to previously described methods (Burrell et al., 1974). Ascitic fluids yielding at least four units of antiglobulin consumption against the insoluble antigen or fibroblasts from cell culture were pooled and stored at $-20^{\circ} \mathrm{C}$ until needed. Such ascitic fluid did not contain detectable rheumatoid factor or antibody against adjuvant components.

\section{Cell culture}

Mouse fibroblasts (L-929) were grown in Eagle's basal medium (BME) containingsodium bicarbonate buffer and supplemented with $10 \%$ fetal calf serum. All cell cultures were incubated at $37^{\circ} \mathrm{C}$ in $5 \% \mathrm{CO}_{2}$ in air. The cells were maintained in BME with $2 \%$ fetal calf serum at $28^{\circ} \mathrm{C}$. Antibiotics when used were penicillin $(100 \mathrm{U} / \mathrm{ml})$, streptomycin $(50 \mu \mathrm{g} / \mathrm{ml})$, and gentamicin $(50 \mu \mathrm{g} / \mathrm{ml})$. All fetal calf sera were heat inactivated.

Peritoneal exudate cells (PEC) were obtained from mice stimulated with $0.5 \mathrm{ml}$ of $1.0 \%$ proteose-peptone, injected intraperitoneally. Four to six days after the injection of the proteose-peptone, the mouse peritoneal cells were recovered by injecting $5.0 \mathrm{ml}$ Hanks' balanced salts solution (HBSS) into the peritoneum, massaging the abdomen gently, killing the animal by cervical dislocation, and finally withdrawing the fluid through a small abdominal incision with a capillary pipette. The 
cells were washed once with HBSS containing penicillin, streptomycin, and gentamicin, and then suspended in Medium 199 (Gibco, Grand Island, NY) containing $15 \%$ calf serum and the same antibiotics. The cell concentration was adjusted to $10^{6}$ cells $/ \mathrm{ml}, 3.0 \mathrm{ml}$ volumes placed in $47 \mathrm{~mm}$ plastic petri dishes, and incubated at $37^{\circ} \mathrm{C}$ in humidified $5 \% \mathrm{CO}_{2}$ in air.

\section{Assay for fibrogenic activity}

The fibrogenic activity of the lung antibodies was tested directly on L-929 mouse fibroblasts and indirectly on mouse PEC by adding supernatant fluids from lung antibody treated PEC cultures on fresh L-929 fibroblast cultures. L-929 mouse fibroblasts were grown in $114 \mathrm{ml}$ prescription bottles for 24 to 36 hours until they had reached a stationary phase. Because of initial negative results, $50 \mu \mathrm{g} / \mathrm{ml}$ ascorbic acid was added to the growth and maintenance media. The media were then changed and BME maintenance medium was placed on the cells. To this, various concentrations of filter-sterilized, lungreactive ascitic fluid were added, and collagen production as determined by hydroxyproline measurement was assayed at $1,3,4,6$, and 12 days after exposure to the lung antibodies.

The indirect assay was accomplished by washing PEC cultures 24 hours before harvesting with BME growth medium to remove nonadherent cells, and then incubated for 24 hours in BME growth medium containing a 1/20 dilution of lung-reactive ascitic fluid. The PEC culture fluid was then removed and added to L-929 fibroblast target cell cultures. After 4 and 6 days of contact, the supernates were assayed for hydroxyproline. The cell sheet was recovered by trypsinization and the total cell count and total DNA for each bottle were determined. All ascitic fluids were heat inactivated before assay.

\section{Biochemical methods}

Hydroxyproline determinations were made according to the method of Switzer and Summer (1971). DNA assays were performed by the use of Burton's (1962) modification of the diphenylamine method.

\section{Results}

Direct cytotoxic effects of immune ascitic fluid were determined by growing fibroblasts in media containing various dilutions of the lung antibody-containing ascitic fluid. Only the lowest dilution (1/10) showed any cytotoxic effects. From cytotoxic studies and fluorescent antibody procedures it became apparent that there was a range of antibody concentrations in which the antibodies reacted with the cells, but in which cytotoxic effects were not evident. Subsequent experiments using these antibodies were carried out at antibody concentrations in the subcytotoxic range

Fibrogenic activity associated with the lung antibody was assayed in two ways. Direct fibrogenic activity was tested by culturing the fibroblasts with antibody for various lengths of time. Indirect fibrogenic activity was determined first by exposing mouse macrophages to antibody and then by placing the media from these cultures on fibroblast target cell cultures. The supernatant media from these cultures were assayed for hydroxyproline. Since data collected during experiments on direct fibrogenic activity showed that there was a good linear correlation between cell counts and DNA concentrations, in later experiments only total cell counts were made. Because BME maintenance media contained low concentrations of hydroxyproline and these varied somewhat from batch to batch of BME, fresh medium was always included as a control. The concentration of hydroxyproline in fresh medium was subtracted from the concentration in spent test medium to determine the amount of hydroxyproline produced by the culture. The results are expressed as $\mu \mathrm{g}$ hydroxyproline produced per $10^{5}$ cells (Table 1).

TABLE 1

Hydroxyproline Production by Fibroblasts Exposed to Lung Antibodies

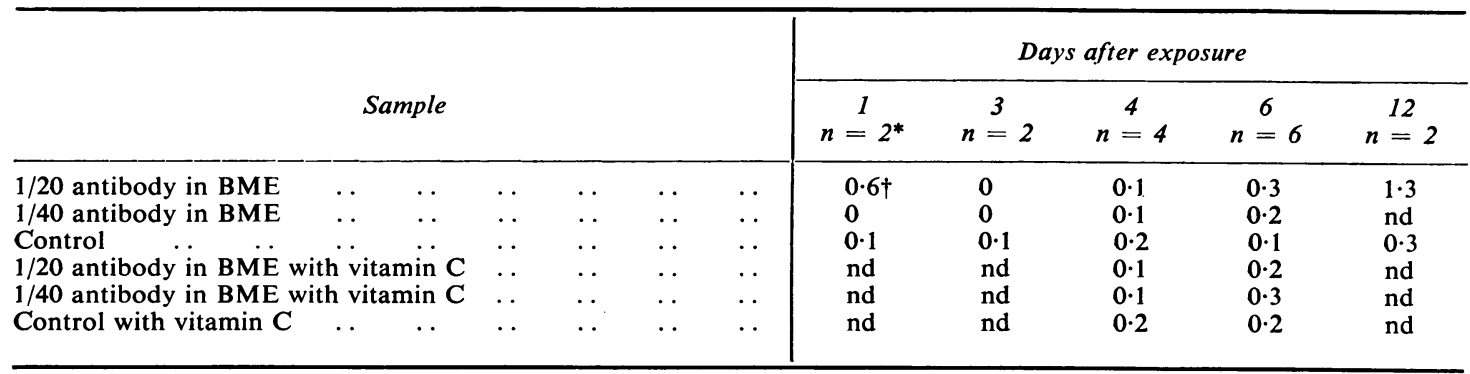

*Number of experiments, each of which was done in duplicate.

†Amount of hydroxyproline (HYP) produced $=[\mathrm{HYP}(\mathrm{S})-\mathrm{HYP}(\mathrm{F})] \div \mathrm{N}$

nd $=$ not done

Where, HYP (S) is concentration of hydroxyproline in spent media HYP (F) is concentration of hydroxyproline in fresh media and $\mathrm{N}$ is the cell count times $10^{5}$. 
Because the results of direct assay in this study were so uniformly negative, it was felt that the culture medium used possibly contained insufficient amounts of vitamin $C$ for collagen synthesis. Therefore, the experiment was repeated using medium supplemented with $50 \mu \mathrm{g} / \mathrm{ml}$ ascorbic acid (Schafer et al., 1967). The last three lines of Table 1 show these results. As before, no significant amount of hydroxyproline was found in the culture fluid, implying that collagen synthesis had not been stimulated. In Table 1 , the $1 / 20$ antibody - 12-day samples show some apparent increase in hydroxyproline concentration, but this figure may be artificially high since the cell population was declining due to exhaustion of the media, while the actual hydroxyproline concentration remained constant. In all other instances cell counts remained constant.

Assays for indirect fibrogenic activity proved more fruitful. In these experiments, media from lung antibody treated macrophages were incubated with the fibroblast target cells. For a known positive control, medium from a previous study (Burrell and Anderson, 1973) in which silica-treated macrophages were shown to be highly stimulatory for collagen, was employed and still found to incite target cell hydroxyproline production even after two years' storage in the freezer. Table 2 shows that hydroxyproline concentrations were elevated in fibroblasts treated with samples from macrophages exposed to the lung antibodies, although not to the same level as the positive control. This increase in hydroxyproline concentration was statistically significant $(P<0.005)$ in the six-day samples.

\section{Discussion}

The idea of using an in vitro model of fibrogenesis originated with Heppleston and Styles (1967) who employed two cell cultures to show the fibrogenic effect of silica. This work has been confirmed (Burrell and Anderson, 1973), although negative results have also been reported (Harington et al.,
1973). Kilroe-Smith et al. (1973) extended these observations back to the in vivo situation by demonstrating a lipid free fibrogenic factor in alveolar macrophages isolated from silicotic guinea-pigs and by showing that this factor induced fibrosis when implanted under guinea-pig skin. Richards and Wusteman (1974), although unable to show collagen stimulation with medium supernates from silicatreated macrophage cultures, were able to show some stimulation using disrupted silica-treated macrophages and an even greater stimulation using intact untreated macrophages. They suggested that the intact macrophage making physical contact with the fibroblast was necessary to stimulate collagen synthesis.

Harington (1974) recently summarized the studies of experimental in vitro fibrogenesis and concluded that the state in which the target cells were at the time of stimulation, whether actively dividing or resting, had a great deal to do with stimulation or inhibition of collagen synthesis. He postulated that resting cells were inhibited from synthesizing collagen by appropriate stimuli. Our results do not support this hypothesis. Although we did not measure by an accurate method (for example, by tritiated thymidine uptake) whether our cells were dividing or at rest, all fibroblast cultures used in these experiments had reached a stationary phase as determined by gross observation.

Although hydroxyproline was chosen in these and the present studies as a convenient marker to indicate collagen synthesis, biochemists working on connective tissue believe that true collagen may not exist in fibroblast cell cultures, but in the form of collagen precursors. Therefore strictly speaking, when we refer to collagen production we are actually speaking of hydroxylation of proline to hydroxyproline, and this happens only when proline is incorporated into the $\alpha$ chain of the collagen precursor. The main point is that by using this model monitored by hydroxyproline production, the investigator has a convenient model for the study of in vitro fibro-

TABLE 2

IndiReCt Fibrogenic Activity of Lung Antibodies

\begin{tabular}{|c|c|c|c|c|c|c|c|c|c|}
\hline \multirow{2}{*}{\multicolumn{7}{|c|}{ Medium from macrophages }} & \multirow{2}{*}{$\frac{\text { Dilution }}{1: 1^{*}}$} & \multicolumn{2}{|c|}{ Age of fibroblast culture } \\
\hline & & & & & & & & $\frac{4 \text { Days }}{0.52 \dagger}$ & $\frac{6 \text { Days }}{2 \cdot 0}$ \\
\hline $\begin{array}{l}\text { Lung antibodies }(n=5) \\
\text { Lung antibodies }(n=6) \\
\text { Silica }(n=2) \\
\text { Silica }(n=2) \\
\text { Nonreactive ascitic fluid }\end{array}$ & $\begin{array}{l}\cdots \\
\cdots \\
\cdots \\
\cdots\end{array}$ & $\begin{array}{l}\cdots \\
\cdots \\
\cdots \\
\cdots \\
\cdots\end{array}$ & $\begin{array}{l}\ldots \\
\cdots \\
\cdots \\
\cdots \\
\cdots\end{array}$ & $\begin{array}{l}\cdots \\
\cdots \\
\cdots \\
\cdots \\
\cdots\end{array}$ & $\begin{array}{l}\cdots \\
\cdots \\
\cdots \\
\cdots \\
\cdots\end{array}$ & $\begin{array}{l}\cdots \\
\cdots \\
\cdots \\
\cdots \\
\cdots\end{array}$ & $\begin{array}{l}1: 1^{*} \\
1: 5 \\
1: 1 \\
1: 5 \\
1: 1\end{array}$ & $\begin{array}{l}0.52 \dagger \\
0 \cdot 1 \\
1 \cdot 5 \\
0 \cdot 1 \\
0 \cdot 2\end{array}$ & $\begin{array}{l}2 \cdot 0 \\
0 \cdot 3 \\
3 \cdot 1 \\
0 \cdot 4 \\
0 \cdot 4\end{array}$ \\
\hline
\end{tabular}

* Medium from macrophage culture was either directly placed on fibroblast cultures, or diluted 1:5 with fresh medium †Average $\mu \mathrm{g}$ of hydroxyproline produced per $10^{5}$ fibroblasts from five determinations 
genesis, whether from the biochemical, immunological, or cellular point of view.

The present study clearly shows that although lung antibody is not collagen stimulating when directly applied to fibroblasts, it becomes so indirectly after reacting with macrophages. The possibility that intact macrophages or cellular debris contaminants were necessary for demonstrating this stimulation cannot be ruled out since the macrophage supernates were not filtered before transfer. It is, therefore, possible that the present phenomenon is similar to that described by Richards and Wusteman (1974).

It appears that lung antibodies are reactive in vivo by stimulating reticulin or collagen rich hyaline thickening of the interalveolar septa (Burrell et al., 1974). It is felt that this in vitro model may help to explain how it happens.

Vigliani and Pernis (1959) originally postulated that silica stimulated macrophages to release an autoantigen which in turn initiated lung antibody production. They concluded that the hyaline material seen in silicotic lungs was antibody complexed with autoantigen. More recent studies have shown that a component of the hyaline material is collagen (Burrell et al., 1974) and that collagen is the primary antigen reactive with lung antibodies (Burrell et al., 1966). The present study modifies Vigliani and Pernis's view that the antibody does react with macrophages, but suggests that the consequences of this reaction are somewhat different. It now appears that the antibody stimulates macrophages to release a fibrogenic factor and its action stimulates collagen synthesis resulting in the production of more antigen.

These results do not prove whether it is an anticollagen factor, another antibody, or a nonspecific serum factor which stimulates the macrophages to initiate the effect on fibroblasts. If it could be shown that a single antibody were responsible for reacting with the same specificity on both the macrophage and the fibroblast then such a finding would lend support to the controversial hypothesis that some fibroblasts may be derived from macrophages. Apart from this, lung connective tissue antibodies may be added to the list of known fibrogenic agents

\section{References}

Burrell, R. and Anderson, M. (1973). The induction of fibrogenesis by silica-treated macrophages. Environmental Research, 6, 389-394.

- Esber, H. J., Hagadorn, J. E., and Andrews, C. E. (1966). Specificity of lung-reactive antibodies in human serum. American Review of Respiratory Disease, 44, 743-750.

, Flaherty, D. K., DeNee, P. B., Abraham, J. L., and Gelderman, A. H. (1974). The effect of lung antibody on normal lung structure and function. American Review of Respiratory Disease, 109, 106-113.

- Wallace, J. P., and Andrews, C. E. (1964). Lung antibodies in patients with pulmonary disease. American Review of Respiratory Disease, 89, 697-706.

Burton, K. (1962). Determination of DNA concentration with diphenylamine. Methods in Enzymology, 12, 163-166.

Esber, H. J. and Burrell, R. (1970). Further characterization of the specificity of lung-reactive antibodies in human serum. Archives of Environmental Health, 21, 502-507.

Harington, J. S. (1974). Fibrogenesis. Environmental Health Perspectives, 9, 271-279.

, Ritchie, M., King, P. C., and Miller, K. (1973). The in vitro effects of silica-treated hamster macrophages on collagen production by hamster fibroblasts. Journal of Pathology, 109, 21-37.

Heppleston, A. G. and Styles, J. A. (1967). Activity of a macrophage factor in collagen formation by silica. Nature (London), 214, 521-522.

Kilroe-Smith, T. A., Webster, I., Van Drimmelen, M., and Marasas, L. (1973). An insoluble fibrogenic factor in macrophages from guinea-pigs exposed to silica. Environmental Research, 6, 298-305.

Richards, R. J. and Wusteman, F. S. (1974). The effects of silica dust and alveolar macrophages on lung fibroblasts grown in vitro. Life Sciences, 14, 355-364.

Schafer, I. A., Silverman, L., Sullivan, J. C., and Robertson, W. V. B. (1967). Ascorbic acid deficiency in cultured human fibroblasts. Journal of Cell Biology, 34, 83-95.

Switzer, B. R. and Summer, G. K. (1971). Improved method for hydroxyproline analysis in tissue hydrolyzates. Analytical Biochemistry, 39, 487-491.

Vigliani, E. and Pernis, B. (1959). An immunological approach to silicosis. In Proceedings of the Pneumoconiosis Conference, edited by A. J. Orenstein, pp. 395-407. Churchill, London.

Received for publication 1 April 1975.

Accepted for publication 4 August 1975. 